On a suggéré aussi l'introduction, dans les viviers, de menu fretin vorace qui happerait les larves de Salmincola à leur stade de vie libre.

Mais comme, la plupart du lcmus, ces mesures sont de simples palliatifs n'aboutissant pas à l'extermination du parasite, il semble qu'au bout du compte, en cas d'épidémie, le moins onéreux soit de se défaire de tous les Poissons et de recommencer l'élevage arec un nouveau cheptel. Ceci suppose que l'eau d'alimentation ne charrie pas de larves de Salmincola, cas auquel on aurait alors à recourir aux filtres à sable.

(A suivre).

\title{
AMÉNAGEMENT DES ÉTANGS
}

\section{Par M. MONTENS D'OOSTERWYCK}

Pisciculteur à llemptinne-en-Condroz (Belgique) (1)

Tout étang destiné à la pisciculture doit, selon nous, posséder ce qui suit :

$I^{\circ}$ Un trop-plein ;

$2^{\circ}$ Une hausse de fond ;

$3^{\circ}$ Une vanne de vidange ;

$4^{\circ}$ Une pêcherie ;

$5^{\circ}$ Si possible un vivier.

$I^{\circ}$ Le trop-plein est destiné à permettre l'écoulement des eaux en excès. 11 sera formé d'un mur en béton de hauteur appropriée. Il pourra aussi itre formé par deux murs distant par exemple de $1 \mathrm{~m}$. 6o et même de quatre rainures en fonte de $40 \mathrm{~mm}$., deux minures pouvant recevoir des madriers, les deux autres un chassis mobile. Dans l'un ou l'autre cas, le châssis mobile sera placé noyé devant le trop-plein. Par exemple, pour un châssis de o m. 6o de hauteur, l'eau arrìcera à o m. 5o de hauteur. De plus il faut prévoir, en cas d'obstruction ou de fortes crues d'eau, l'écouIf ment par-dessus le chìssis de o m. 6o. La digue sera done o m. 20 au moins plus haute.

Les châssis sont formés en fer équerre de $35 \mathrm{~mm}$. et recouverts de tôle perforée appropriée. La grandeur des trous dans celte tôle sera déterminée par la taille du poisson à retenir. Lorsque la quantité d'eau à laisser passer est très considérable, il y aura avantage à incliner les châssis, tel que cela se pratique devant les moulins et turbines hydrauliques. Cela permet leur nettoyage au rateau. Si le débit le demande, on placera plusieurs châssis toujours interchangeables.

(I) Rapport présenté au Congrès international de pisciculture d'Anvers (27-28 juin (ด3̄o).

Article available at http://www.kmae-journal.org or http://dx.doi.org/10.1051/kmae:1930013 
$2^{\circ}$ La hausse de fond est une caige en béton haute denviron o m. 7j à I mètre, placée devant la vanne de vilange. Elle possède une vanne de 4o centimètres de diamètre placéc droite et dans le prolongement de la vanne de fond. Cette vanme est une simple glissière en fonte coulissant sur un châssis égalenient en fonte et possédant une ouverture de 40 centimètres de diamètre. Le but de cetle hausse de lond est de retenir, lors des leeches tout ou partie du poisson; de plus, elle facilite la surveillance le jour de la pêche.

$3^{\circ}$ Vidange de fond. - Les anciens pions ou bundes yui servaient anté neurement pour les vilangres sont à proserire. Hs ne permettent pas fac lement la fermeture momentanéc pendant la piche. Par suite de l'écoulement de l'eau sous pression à angle droit, le poisson se blesse facilement. Les vannes de fonte en tabatière (beaucoup employóes en France) sont '́galement à proserire. Il est presque impossible de les fermer pendant la vidange et, si on y arrive, il se produit une fermelure brusque qui n'est pas sans danger pour le siège de fermeture el même pour la tuyauterie (coup de bélier). Les vannes, telles que l’industris en fournit, ont l'inconvénient de coûter fort cher ; de plus les eaux dés ćlangs étant toujours très chargées de débris divers, ils se logent dins leur intéricur. La pratique nous a conseillé l'usage d'une simple vanne formée d'une glissière en fonte coulissant dans un châssis egalement en fonte. L. lout fixé au bout de la tuyauterie. Cette glissitre est placte suivant linclinaison de la digue de l'étang et à l'intérieur de la cage ou hausse de fond dont il est question cidessus. Cett disposition a l'avantage d'ùtre simple, très solide et à bon marché. Les tuyaux de vidange seront toujours en fonte et de calibre spproprié au volume d'eau a laisser écouler. Cetts luyauteric étant droite depuis l'étang jusqu'à la sortie, son obluration n'est jamais à craindre, quel que soit le diamètre de celle-ci ; l'extrémitó, còté étang, sera coupée en sifflet. Sur celui-ci sera conchés la vanne grlissière qui sera mancuvrée soit par un simple crochet ou bion par une mécanique quelconque genre cric ou vis.

$4^{\circ}$ La pêcherie sera forméc par un rhâssis en béton horizontal sur lequel seront placés le ou les chissis amovihles (ceux des trop pleins). Elle sera de préférence située au bas de la diggue à la sortie lu tuyau de vidange.

Le poisson ne sera plus qu'à mamasser sur les châssis, lors de la péche.

$5^{\circ}$ Il est toujours très ulile de créer un petit vivier à còlé ou le plus près possible de la pêcheric. Il permettra de tenir momentanément tout le poisson vivant et d'en faire le triage. Il sera toujours construit en béton. 